\title{
The new Population Register at Statistics Austria Conceptualization and Methodology for Register-based Flow and Stock Statistics
}

\author{
Gustav Lebhart ${ }^{1}$, Christian Neustädter ${ }^{2}$ and Josef Kytir ${ }^{1}$ \\ ${ }^{1}$ Statistics Austria, Directorate Population Statistics \\ ${ }^{2}$ Statistics Austria, Information Technology Division
}

\begin{abstract}
With Statistics Austria's new population register (POPREG) it is possible to display the population stock and flow for specific points in time and periods for all territorial sub-units in Austria. POPREG is probably the first population register worldwide in which stock and flow data for all relevant demographic categories are conceptualized under common methodological criteria. Thus the population stock no longer has to be estimated and/or annually updated. The multi-level plausibility checks of the Central Register of Residence (CRR) data on registrations and deregistrations of usual places of residence and of the CRR data on residents with their current main place of residence allow for an improvement in the quality to explain demographic processes. Statistics Austria's new population register thereby forms a central component of Austria's statistical system. It provides data on population structure and population development and at the same time forms the central information base for migration statistics. In the future, new synthesis statistics (census register) will be able to be produced through a networked analysis of available register data (e.g. criteria from POPREG networked with criteria from the building and dwelling register or the register of education).
\end{abstract}

Zusammenfassung: Mit dem neuen bevölkerungsstatistischen Register (POPREG) der Statistik Austria ist es möglich, den Bevölkerungsstand und die Bevölkerungsbewegungen für beliebige Stichzeitpunkte bzw. -perioden für verschiedene Gebietseinheiten Österreichs auszuweisen. Das POPREG ist vermutlich weltweit das einzige Register-basierte System, in dem Bevölkerungsstände und -bewegungen für alle wesentlichen demographischen Kategorien nach einheitlichen Kriterien harmonisiert sind. Somit muss der Bevölkerungsbestand zukünftig nicht mehr geschätzt bzw. jährlich fortgeschrieben werden. Die mehrstufigen Plausibilitätskontrollen der aus dem Zentralen Melderegister (ZMR) übermittelten Daten über An- und Abmeldungen sowie über aufrechte Hauptwohnsitze gewährleisten eine Qualitätsverbesserung hinsichtlich der Erklärung demographischer Entwicklungen. Das neue Bevölkerungsregister der Statistik Austria stellt damit einen zentralen Baustein des statistischen Systems Österreichs dar. Sie liefert Angaben über Struktur und Entwicklung der Bevölkerung und bildet gleichzeitig die zentrale Informationsbasis für die Wanderungsstatistik. Durch die vernetzte Auswertung vorhandener Registerdaten (z.B. von Merkmalen aus dem POPREG mit Merkmalen aus dem Gebäude- und Wohnungsregister oder Bildungsstandregister) sind zukünftig neue Synthesestatistiken möglich (Registervolkszählung).

Keywords: Migration Statistics, Measurement Concepts, Austria. 


\section{Introduction}

Population statistics in Austria was traditionally based on the censuses made every ten years, the births and deaths which were continuously recorded by the registry offices (natural population change statistics), naturalizations registered by the regional government offices (naturalization statistics) and - since 1996 - the information received by Statistics Austria from around 2350 local reporting authorities (municipalities) on registrations and deregistrations due to main (usual) places of residence being moved over municipality borders (migration statistics 1996 to 2001). The state of the population in each previous census, arranged by age (year of birth), gender, federal state and nationality categories (Austrians, former Yugoslavs, Turks and other foreigners), was carried forward quarterly with the aid of statistics on births and deaths, naturalization and migration. Before 1996, migration flows were not available at all and migration balances were estimated. From 1996 the municipalities also made an annual record of the number of people with a registered usual place of residence arranged by sex and/or nationality categories. However, this 'inhabitant survey' was difficult to integrate into the demographic system as the municipality calculations for the federal states. As migration balance estimates needed before 1996 could only be made on the basis of incomplete information, the population figures had to be amended every ten years, when new census results were available. Any discrepancy between the census results and those based on the extrapolation of the 'expected' population was statistically eliminated retrospectively by dividing it up among the calendar years since the last census ('population rewriting'). Last time, in the 2001 census, this discrepancy was of approximately 100.000 people or $1.2 \%$ of the total population (Kytir, Lebhart, and Neustädter, 2005).

The basic conditions for population statistics changed in two ways with the 2001 census: Firstly, the Central Register of Residence (CRR) based on electronic data processing, established at the end of the 2001 census, started operating on 1 March 2002. Already at the end of 2001, the obligation of municipalities to deliver data needed for migration statistics ended. Since then, individual registrations and deregistrations of main (usual) places of residence have to be sent to Statistics Austria from the CRR in electronic form, as set out in the Registration Act. Additionally, Statistics Austria receives quarterly a file of people registered in the CRR with a main (usual) place of residence. People in Austria are obligated to register and deregister their main place of residence within three working days. Generally, two types of residences are to be differentiated: the main (usual) place of residence and the secondary place (unusual) of residence. By law, each person in Austria may have only one main (usual) place of residence but can have more than one secondary place of residence. All data records delivered by the CRR contain the so called CRR number which is a unique identifier for each resident in Austria. Secondly, the council of ministers decision in June 2000 documented the political will to carry out no further censuses by surveying the people, but to prepare a register census for 2010 (Kytir et al., 2005).

These amended basic conditions made it necessary and possible to construct a new demographic system which mainly processes individual data by main (usual) residence. The state of the population is now no longer ascertained by updating demographic aggregates, but rather by aggregating individual data records of residence at the time of evaluation. 
Migration statistics is derived from the same individual data records by detecting changes of main (usual) places of residence. The CRR itself has not been designed to immediately meet the demands of population or migration statistics. Hence, at Statistics Austria the CRR data is not evaluated directly but first processed using a database which contains historical data and is refreshed whenever new data is supplied from the CRR. Data sets for statistical purposes are generated from this database. The "statistical twin" of the CRR is called POPREG ("POPulation REGister"), which constitutes the basis for the new register-based demographic system at Statistics Austria.

\section{The Conceptual Design of the Population Register 'POPREG'}

\subsection{Data Source}

Generally, no country in the world has one single source that adequately reflects the growing complexity of population development and migration dynamic. A variety of data sources, including household surveys, border statistics, administrative registers and other administrative data, produce different types of population and migration statistics, each with its own strengths and limitations (United Nations, 2002, p. 9).

Statistics Austria receives two data files as sources for population and migration statistics from the Central Register of Residence (CRR): (a) data records on all registrations and deregistrations of main (usual) places of residence during the previous quarter of the calendar year (flow data) and (b) data records of current main (usual) places of residence registered in the CRR (stock data), which are both reported at the end of each quarter of the calendar year.

\subsubsection{Flow Data}

Flow statistics is a complex and politically sensitive subject that can be difficult to define and to measure. Therefore, special attention needs to be paid to the coverage and quality of flow data being collected, compiled and used for different purposes. Compared with data on fertility and mortality, gathering international migration data is problematic in nearly all countries in the world and the statistics needed are very often lacking. While birth and death constitute singular demographic events in an individual's life, migration may occur repeatedly, which contributes further to the difficulties of its adequate measurement.

The files of flow data received from the CRR contain one record for each registration and each deregistration of a person with a main (usual) place of residence (including registrations due to birth and deregistrations due to death). The data records contain data attributes concerning

- the person (e.g. CRR number as PIN, date and country of birth, sex, nationality),

- the place of residence (e.g. record key, address, ID number of the building),

- the type of registration or deregistration (codes for birth, immigration, change of place of residence within Austria, emigration, death, correction, etc.), 
- the country of origin in the case of immigration,

- the country of destination in the case of emigration,

- the official dates of registration and deregistration resp. of the place of residence,

- the time of processing the registration or deregistration resp. in the CRR.

Files of flow data are delivered for specific periods and contain all registrations and deregistrations whose time of processing in the CRR falls within this period, regardless of the official dates of registration and deregistration. Generally, the periods of delivered flow data fully cover time since 1 January 2002 without overlapping and start/end only at that points in time for which stock data is available. Since 1 January 2004, the periods constitute exactly one calendar quarter (before 1 January 2004 see the below information on stock data). One quarterly supply currently includes between 400.000 and 600.000 registrations and deregistrations.

\subsubsection{Stock Data}

In principle, population statistics refers to the concept of residential population ("permanent residents') which identifies the number of inhabitants at a certain time-point (e.g. 1 st January of each year) vicariously for a period (annual average). However, this poses problems for the adequate recording of population groups who do not have a principal domicile in the country (or in the municipality) during the complete reference period. As a consequence statistical implications on the population stock at a specific time-point as well as on the classification of migration within the reference period are necessary.

With each data delivery from the CRR, Statistics Austria receives a file of population stock affiliated to the file of population flow, where the population stock refers to that point in time which is equal to the end of the period for which the population flow is delivered. The files of stock data contain one record for each main (usual) place of residence whose official date of registration lies before that time-point and whose official date of the corresponding deregistration lies after it or whose corresponding deregistration has not taken place. The data records contain the same attributes as those of the flow data files.

\subsection{Components of POPREG}

As Statistics Austria does not have direct access to the CRR and since data values may be imputed or corrected due to violations of plausibility constraints, actions had to be taken to ensure coherence of statistics gained from CRR data.

This is achieved by organizing all - even historical - data from the CRR in database tables at Statistics Austria, which are updated with each data supply from the CRR. Plausibility checks and imputation are done before insert/update of the database tables. Then files for population stocks, demographic events and citizenship transitions are generated from these tables, from which, finally, statistical information on inhabitants and migration are derived (see Figure 1).

Data records received from the CRR do not contain names of people but include CRR numbers to identify a person (and hence allow to find all residences belonging to the same 
person). All residences are identified by record keys so that registrations and corresponding deregistrations can be joined. The data of all registrations and deregistrations are split into three groups of attributes which constitute the database tables of POPREG:

- the table of residents (with attributes concerning the person: CRR number, date and country of birth, sex, etc.),

- the table of residences (with attributes concerning the residences of people: CRR number, record key, various address attributes, the type of registration and deregistration, the country of origin/destination in the case of immigration/emigration, the official dates of registration and deregistration, the time of processing the registration/deregistration in the CRR etc.) and

- the table of citizenships (with attributes concerning the citizenships of people: CRR number, nationality, dates of validity).

These tables were first filled using the data from the CRR on 31 December 2001 24:00:00.

\subsection{Data Processing in POPREG}

The data received from the CRR is put through a number of processing steps:

- The micro plausibility checks of registrations and deregistrations include a systematic examination of the formal validity of criteria and the consistency of dates (date of birth and - if present - date of death, official dates of registration and deregistration, dates of processing the (de)registration in the CRR). Furthermore, missing values on the country of birth, country of origin and/or destination and nationality are imputed and flagged as imputed values.

- The macro plausibility checks of registrations and deregistrations firstly examine the consistency of all dates with the dates in database tables. Then database tables are updated with the data on registrations and deregistrations. All updates of database tables of POPREG observe three principal laws: First, all known values are treated preferentially (concerns only the variables citizenship and country of birth since only there can exist a value 'unknown'). Second, non-imputed values overwrite imputed values. Third, current values (any registration which is just processed compared to those in the database) do always update non-current values. For example, in the case of nationalities all entries are carried out according to the general plausibility rules and status expressions (' 0 ' for non-imputed, ' 1 ' for imputed) are taken from the micro plausibility. If a data set is produced, the features and markings will also be taken for other features with status markings. When updating the features, markings are carried out according to the fixed priority of the plausibility rules.

- In the next step the file of the CRR which contains stock data is compared to the current state of the database tables of POPREG, and information gets updated if necessary. As values like citizenship may change independently of registration and deregistration, this step is necessary in keeping the data in the database tables of POPREG up-to-date. 


\subsection{Authentic Data Files}

After the update of the database tables, files for population stocks, demographic events and citizenship transition are generated. For these data masses the period of time and the point in time respectively have to be specified. Generally, a period of observation is given for the production of the following files from the database tables (see Figure 1):

- Table of resident information contains the population stock at the beginning and at the end of the given period, where the population stock at a certain point in time is understood to be the mass of persons for which a registration of a main place of residence lies before that certain point in time and the corresponding deregistration lies after it or has not taken place (see Subsection 3.1).

- Table of residence information mirrors the changes of main (usual) places of residence of the population in the given period, which contain records for immigration and birth (i.e., for the first registration of a person at all or straight after a period of being not registered for more than 90 days), emigration and death (i.e., for the last deregistration of a person at all or straight before a period of being not registered for more than 90 days) and internal migration. For each registration at a main (usual) place of residence, which is linked to an address different from that of the main (usual) residence where the person had been registered straight before and within the last 90 days (see Subsection 3.2).

- Table of citizenship information refers to the changes of citizenships of the population in the given period, which documents naturalization events in the respective observation period.

The changes of main places of residence, including births and deaths, (combined with the changes of citizenship) accurately explain the population at the end of the period on the basis of the population at the beginning of that period for any territorial sub-unit of Austria (for any nationality or for the whole population). This is not the case with the files originally delivered by the CRR. It should be noted that the update status of the database tables of POPREG (meaning which data supplies from the CRR have been used for updating the tables so far) also influences the resulting masses as registrations and deregistrations are processed with delay in the CRR and hence may be delivered later than expected. The records of the population stocks contain at most one record per person, whereas the files for both migration flows and changes of citizenship consist of records for the events of change, of which each person can have none, one or more than one.

The population stock is used to determine the number of inhabitants of Austria and its territorial units for any point in time since 2001. The records contained in the file demographic events are classified by demographic considerations as birth, death, internal migration, immigration, emigration and as events which cannot be classified demographically. This classification is used as a basis for the calculation of the components of population change as well as for producing migration statistics. The challenge is that the types of (de)registration provided by the reporting authorities do not always state plausible information. Therefore, a factually correct mapping of registration procedures to demographic events is not possible solely on the basis of these codes. The changes of citizenships (naturalizations, nationality changes) complete the demographic landscape (Figure 1). 


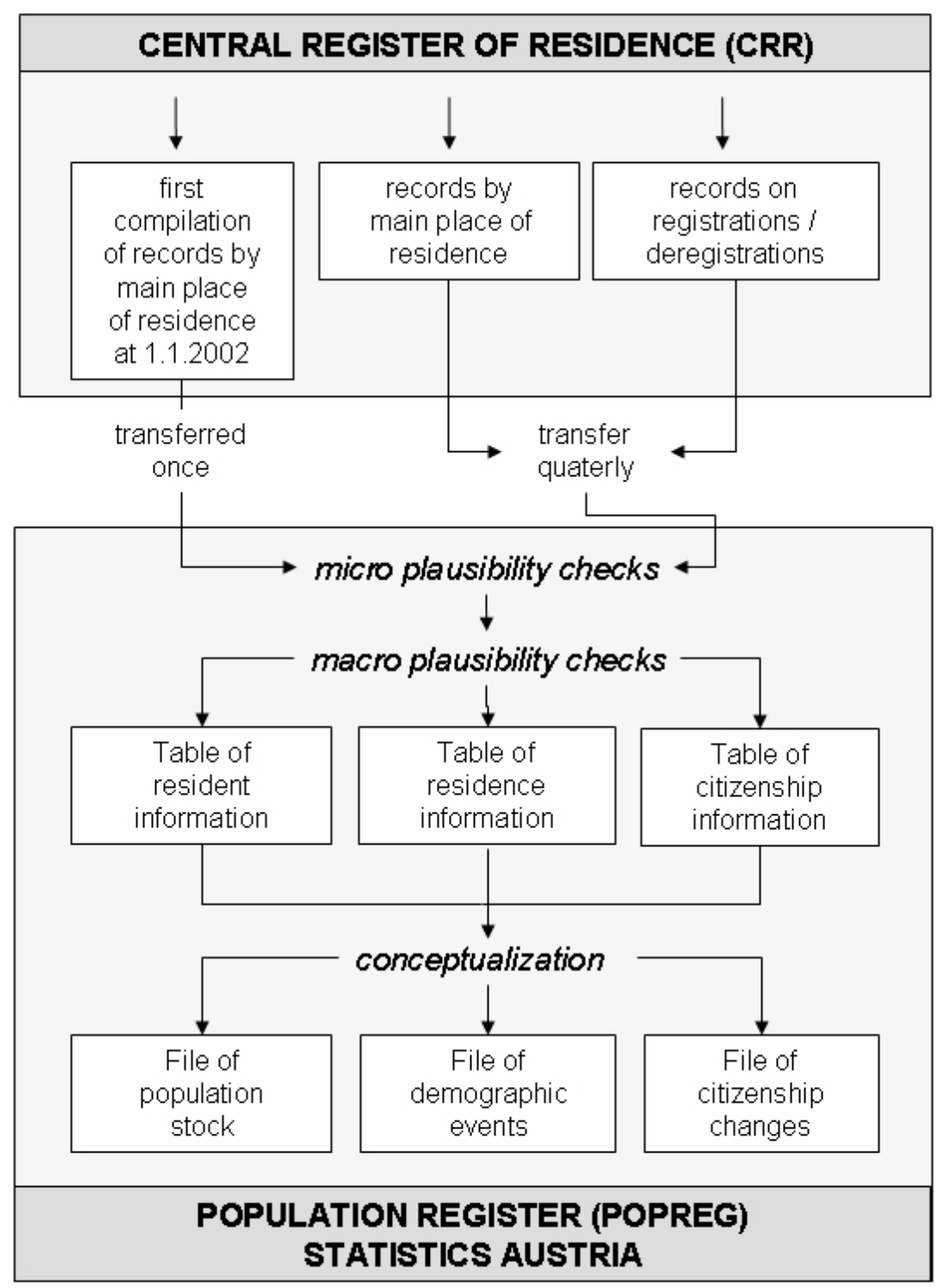

Figure 1: The conceptual design of the Population Register 'POPREG'.

\section{Measurement Concepts for Demographic Events}

\subsection{Conceptualization of Stock Statistics}

The UN Recommendations on Statistics of International Migration defines usual place of a country in which a person lives respectively has a place to live and where he or she normally spends the daily period of rest. Temporary travel abroad for purposes of recreation, holiday, visits to friends and relatives and business does not change a person's country of usual residence (United Nations, 1998a). Do people have their usual residence for at least three months but for less than a year then they are defined as 'short-term migrant'. Since these people have their usual place of residence in another country, the UN suggests that 
they should not be regarded as permanent residents of the country. However, if data are obtained from the census then 'short-term migrants' should be includes in the count of the total population during the period they spend in the host country (United Nations, 1998b).

Pursuant to international recommendations of the UN, the information that is available in POPREG on the residence duration in Austria is consulted to determine the permanent population and international migration figures. Only people who have a minimum residence duration of more than 90 days at the end of the qualifying period are classed as permanent residents in Austria (exception: newly born). Approximately 2.500 till 3.500 people who are registered in Austria at the time of the qualifying period deadline, do not fulfill this criteria. As of the 2002 reporting year, these 'non-migrants' therefore also no longer appear in the migration statistics on people moving into and out of the country (see Table 2). For migration statistics, the residence duration is also used as a criterion for classifying people who have moved into Austria from abroad as 'short-term migrants' (residence duration of at least three months but less than a year) and 'long-term migrants' (residence duration of at least a year).

\subsection{Conceptualization of Flow Statistics}

Comparing migration statistics in countries of origin and destination often shows significant discrepancies in the measuring of the same migration flows, because a common approach on the measurement of stocks and flows is still missing. At present international recommendations and regulations for the statistical recording of international migration flows focus on a 12 months concept. However, this is afflicted with the problem of selectivity as short-term migrations are not at all reflected. With Statistics Austria's population register (POPREG), Austria is, to the best of our knowledge, the first country worldwide where stock and flow statistics are displayed under strict harmonized time criteria.

Specification of the resident population and migration is based on the duration of residence. A specification of the duration of residence is necessary because information from migration statistics should be consulted in future both at European level and for international comparison. A valid duration of residence begins on the registration date, providing no other registration has taken place for at least 90 days prior to this date. The end of the valid duration of residence (completed registration episode) is when at least 90 days after the deregistration date, no further registration has taken place. The date will only be overwritten when a new valid registration date is available. A completed registration episode can therefore consist of several registration events, which are processed in accordance with the requirements. In total, there are three different residence permits depending on the duration of residence:

- temporary stay: from 0 days up to and including 90 days,

- short-term migration: from 91 days up to and including 365 days,

- long-term migration: 366 days or more.

The Council of Europe defines a migrant as 'any person who lives temporarily or permanently in a country where he or she was not born, and has acquired some significant social ties to this country' (Europarat, 2005). The 'UN Convention on the Rights of Migrants' defines a migrant worker as a 'person who is to be engaged, is engaged or has 
been engaged in a remunerated activity in a State of which he or she is not a national' (UNHCR, 1990). The proposed regulation of the European Union on 'Community statistics on migration, and international protection', intends to put the focus of the migration statistics on long-term migration and to register only persons who actually have a principal domicile in the country of destiny longer than a year or declared a stay at the place of residence registration of at least twelve months (European Commission, 2006). Neither the items country of birth nor nationality are referred to explicitly in the definition of (long-term) migration. In the new population statistics at Statistics Austria, people are classed as migrants if they have or had a usual (main) place of residence in Austria for a duration of more than 90 days. On the deadline date, people with a duration of residence of under 91 days are therefore not classed as permanent residents but as temporary stayers.

The following rules do not apply only for international migration but are also relevant for the determination of internal migration flows. Changes of residence where the duration of residence at the new address is under 91 days are also excluded. For internal migration this means that from the approximately 600.000 to 650.000 cases of internal migration per year, only around 1.000 to 1.500 cases are excluded. The international classification of 'short-term migration' is therefore also applied to internal migration. If within 90 days after a deregistration of main (usual) place of residence, a registration of main (usual) place of residence with a different address takes place, this is classed as internal migration, even in the case of a move abroad followed by a return from abroad. On the other hand, if the period without a legal registration of main (usual) place of residence in Austria amounts to more than 90 days, a move abroad and an arrival from abroad are recorded separately in the migration statistics. Changes of main (usual) residence between different apartments within the same building are excluded from the migration statistics.

\subsection{Differences between POPREG and CRR}

Since 1 January 2002 the new demographic system has, in principle, replaced the former system of population updates. The new population register offers numerous advantages, but also has a number of disadvantages (partly with only temporary effect). The most important advantages include:

- the great timeliness in which the number of inhabitants is available. Provisional population figures are already available only a few weeks after the end of the quarter and definitive population figures are available four months after the end of the quarter,

- the in-depth geographical and categorical organization of the number of inhabitants. It is now not only possible to get population figures for municipalities, political districts, NUTS 3 and NUTS 2 regions (Federal Länder) at the time of a census, but also to get continuous population figures, sorted (at request) by age, sex and nationality, which can be consulted, among other things, as a basis for calculating demographic values,

- the improved implementation of international recommendations when generating migration statistics and statistics on the state of the population. 
However, the new population statistics in Austria, at least temporarily, has a number of disadvantages and problems. The transition from the 'old' system to the 'new' system was not possible without a break (even if a comparatively small one) in the time series in the form of statistical adjustments. This means that the 'old' migration statistics for the period after the 2001 census (15th May 2001 to 31st December 2001) displayed a large under-recording of registrations in comparison with the number of registrations recorded in the CRR. A new, far higher migration balance had to be calculated for 2001 to explain the increase in the population. It was also necessary to make a statistical correction to the state of the population at the end of 2001 (approximately +10.000 people) because the clearing measures taken during the 2001 census could not be fully integrated into the CRR. This meant that all demographic measures regarding the population had to be revised for the year 2001. Quality problems in the correct classification of deaths by the reporting authorities mean that, in comparison with the registry office, the number of deaths reported in POPREG is too low while at the same time the number of births is somewhat too high. The balance of births was therefore shown as a component of population change by reverting to the registry office data. This means that slight statistical adjustments had to be made the state of the population.

Nevertheless, the two data sources (the register offices and the CRR) will still continue to supply (slightly) different data on the number of births and deaths. This difference is mostly due to births outside Austria in hospitals close to the border (under-recording in registry office data, particularly in West Austria). However, newborns dying whilst still in hospital are not included in the CRR (under-recording in the registration data). For an accurate state of the population, all registered number of deaths of people, who die whilst abroad (e.g., whilst on holiday), with a registered main (usual) residence in Austria would also have to be documented in the CRR (under-recording in registry office data) (Kytir et al., 2005).

\subsection{Components of the Discrepancies Concerning Registration of People with Main (Usual) Residence in CRR and POPREG}

Firstly, there is a difference between the delivered control data stocks (column a) and the total number of residents published by the CRR (column b) in a range of approximately 50 to 500 , in one case however also approximately 2.700 . This deviation is attributed to the CRR alone and could be justified by specific conditions (e.g. time-points) of data production of the control stock (which will be delivered to Statistics Austria) and the total number of registered residents in the CRR (see Table 1).

Secondly, the comparison between the control data by the CRR (column b) and the POPREG-database (column e) can be explained by following three reasons leading to a further discrepancy.

- A principle difference in the data state can be explained by the fact that Statistics Austria consider even delayed registrations reported in the following quarter. In addition, the conditions for the production of the population stock take into account that in the case of reporting gaps up to 90 days, the duration at the last reported place of residence is extended fictitiously till the next registration. By adjustments, single data sets can be modified in their reporting dates (beginning or end) and regularly 
Table 1: Registration of people with main (usual) residence in Austria (Source: Central Registration Register, CRR, and Statistics Austria, STAT).

\begin{tabular}{|c|c|c|c|c|c|c|}
\hline \multirow[t]{2}{*}{ Date } & Reside & $\begin{array}{l}\text { CRR } \\
\text { e Registrati } \\
\text { officially }\end{array}$ & & \multicolumn{3}{|c|}{$\begin{array}{c}\text { STAT } \\
\text { Population Stock } \\
\text { officially }\end{array}$} \\
\hline & stock data ${ }^{a}$ & published $^{b}$ & diff. & POPREG $^{d}$ & published $^{e}$ & diff. \\
\hline 1.04 .2005 & 8.247 .169 & 8.244 .420 & 2.749 & 8.247 .853 & 8.216 .226 & 31.627 \\
\hline 1.07 .2005 & 8.259 .668 & n.a. & n.a. & 8.260 .731 & 8.229 .498 & 31.233 \\
\hline 1.10 .2005 & 8.277.329 & 8.277 .380 & -51 & 8.280 .989 & 8.251 .331 & 29.658 \\
\hline 1.01 .2006 & 8.293 .626 & 8.293 .106 & 520 & 8.294 .474 & 8.265 .925 & 28.549 \\
\hline 1.04 .2006 & 8.300 .976 & 8.300 .451 & 525 & 8.301 .756 & 8.274 .142 & 27.614 \\
\hline 1.07 .2006 & 8.305 .879 & 8.305 .856 & 23 & 8.306 .684 & 8.279 .571 & 27.113 \\
\hline 1.10 .2006 & 8.316 .406 & 8.316 .394 & 12 & 8.317 .438 & 8.291 .706 & 25.732 \\
\hline
\end{tabular}

Table 2: Population with main (usual) residence in Austria (Source: Statistics Austria, own calculations).

\begin{tabular}{|c|c|c|c|c|c|}
\hline \multirow{4}{*}{ Date } & \multicolumn{5}{|c|}{ Population Stock } \\
\hline & \multirow[t]{3}{*}{ total } & \multicolumn{2}{|c|}{ counted } & \multirow{2}{*}{\multicolumn{2}{|c|}{$\begin{array}{l}\text { not counted } \\
\text { active or reactivated }\end{array}$}} \\
\hline & & & & & \\
\hline & & active & reactivated & inactivated & temporary stayers \\
\hline 1.04 .2005 & 8.216 .226 & 8.209 .484 & 6.742 & 29.350 & 2.277 \\
\hline 1.07 .2005 & 8.229 .498 & 8.221 .745 & 7.753 & 28.202 & 3.031 \\
\hline 1.10 .2005 & 8.251 .331 & 8.242 .649 & 8.682 & 27.034 & 2.624 \\
\hline 1.01.2006 & 8.265 .925 & 8.256 .502 & 9.423 & 26.153 & 2.396 \\
\hline 1.04 .2006 & 8.274 .142 & 8.264 .019 & 10.123 & 25.258 & 2.356 \\
\hline 1.07 .2006 & 8.279 .571 & 8.268 .683 & 10.888 & 23.513 & 2.823 \\
\hline 1.10 .2006 & 8.291 .706 & 8.280 .132 & 11.574 & 23.240 & 2.492 \\
\hline
\end{tabular}

low number of cases has to be rejected due to data sets which can not be corrected at all.

- Approximately 23.000 people are deducted from the population stock in the POPREG database as 'inactivated' registrations (see Table 2).

- 2.000 to 3.000 'temporary stayers' (people, who were not inactivated but retrospectively not more than 90 days registered) are not considered as usual residents in Austria and indicate a further temporal discrepancies of registrations between the CRR and POPREG (see Table 2).

While in the year 2004 the number of reactivations of people who were previously set to 'inactivated' was about more than 400 people, the number increased by 3.700 people within the year 2005 since registered homeless people (about 3.500) were for the first time included in the POPREG. Down to 1st October 2006 there were about 11.600 residents who had been 'reactivated' in POPREG. Such reactivation cause almost 'retrospective' changes in the number of inhabitants which cannot be explained by demographic events of the period in question. Summing up, the number of all main (usual) residence regis- 
trations differs negligible between the CRR and the POPREG. During the first quarter of 2004, the number of inactive people decreased significantly due to executed administrative deregistration (about 60.000) in the CRR. In 2006 the difference between the CRR (column b) and the POPREG (column e) concerning the published number of the total population amounted to a total of about 25.000 to 27.000 people (see Table 1). This difference can mainly be explained by the fact that the CRR still counts people who were not registered at the census 2001 but still reported in the local registers of municipalities (= inactivated registration in POPREG). In addition, the explicit consideration of a minimum duration of stay in POPREG does amplify a difference in the number of residents in Austria.

\section{Conclusion}

Statistics on demographic data from different countries have to be undertaken with care as only few countries have implemented the UN recommendations in their national statistics. In fact, the official population statistics are usually closely linked to concepts and definitions used in the national administrative systems. Thus the lack of standardization in measuring demographic events still remains a key source of inconsistency in population statistics in many countries worldwide. Harmonization of flow and stock data remain still a major task of the National Statistical Institutes. There is a clear need to review and clarify the distinct concepts currently used for population statistics. Different data sources inevitably imply varying data quality which often results in questionable reliability of the characteristics recorded.

With the establishment of the Central Register of Residence (CRR) and its continuous development and improvement in quality by electronic government, the population statistics in Austria has found a new footing. The new 'POPREG', which is based on CRR registration data, opens many new opportunities for demographic analysis for small territorial units and is the source for further detailed analyses in the field of migration statistics. Last not least, with regard to the approaching 2010 register census specialized statistical and computerized expertises are constantly being acquired on the content and quality of the data from this most important population register. One of the tasks over the next few years will be to ensure the consistency of the population register with Statistics Austria building and dwelling register and to transfer address-related data (such as the differentiation between private and institutional households) from this register. On the basis of the above mentioned considerations it can be noted that POPREG could be a relevant demographic information basis for the planned register census in 2010. POPREG is probably the first population register worldwide in which stock and flow data for all relevant demographic categories are conceptualized under common methodological criteria. What is important to stress however is, that the register-based population statistics reached not only a harmonization of stock and flow data but also enables to geo-reference all demographic data. Another point worth considering is that POPREG enables new synthesis statistics using the networked analysis of available register data. The new register-based population statistics could even be in future an information base for broader longitudinal section studies. 


\section{Acknowledgements}

This paper is a strongly modified and an extended version of an article which was published in the Statistical News Bulletin, March 2005 (Kytir et al., 2005).

\section{References}

Europarat. (2005). Migration and integration - basic concepts and definitions. (www.coe.int, Access August 2005)

European Commission. (2006). Proposal for a regulation of the european parliament and of the council on community statistics on migration and international protection. (Version June 2006)

Kytir, J., Lebhart, G., and Neustädter, C. (2005). Von der Bevölkerungsfortschreibung zum Bevölkerungsregister. Datengrundlagen, Konzepte und methodische Ansätze des neuen bevölkerungsstatistischen Systems. Statistische Nachrichten, 3, 203210.

UNHCR. (1990). International convention on the protection of the rights of all migrant workers and members of their families. (G.A. res. 45/158, annex, 45 U.N. GAOR Supp. (No. 49A) at 262, U.N. Doc. A/45/49, Geneva)

United Nations. (1998a). Recommendations on statistics of international migration. (Statistical Papers Series M, No. 58, Rev. 1, New York)

United Nations. (1998b). Recommendations for the 2000 censuses of population and housing in the ece region. (Statistical Standards and Studies, No. 49, New York and Geneva)

United Nations. (2002). International migration report 2002. (Department of Economic and Social Affairs Population Division, ST/ESA/SER.A/220, New York)

Authors' Address:

Gustav Lebhart

Statistics Austria, Directorate Population Statistics

Dpt. Analyses and Prognoses

Guglgasse 13

A-1110 Vienna, Austria

E-mail: gustav.lebhart@statistik.gv.at

Christian Neustädter

Statistics Austria

Information Technology Division

Guglgasse 13

A-1110 Vienna, Austria

E-mail: christian.neustaedter@statistik.gv.at

Josef Kytir

Statistics Austria

Deputy Director, Directorate Population Statistics

Guglgasse 13

A-1110 Vienna, Austria

E-mail: josef.kytir@statistik.gv.at 